\title{
Study of the influence of asphaltenes on modeling of viscosity of Nigerian crude mixtures
}

\author{
A. Miadonye ${ }^{1}$, F. Dan-Ali ${ }^{2}$, R. Onwude ${ }^{2}$ \& O. O. Osirim ${ }^{2}$ \\ ${ }^{I}$ Department of Chemistry, Cape Breton University, NS, Canada \\ ${ }^{2}$ Department of Petroleum Chemistry, \\ American University of Nigeria, Yola, Nigeria
}

\begin{abstract}
In this study, the effect of asphaltenes on the viscosity of Nigerian light crude oils at different temperatures was studied. Different weight per cent of bitumen containing 14 per cent asphaltenes and deasphalted bitumen samples from Alberta, Canada were mixed with Nigerian crude oils. The mixtures were prepared from five light crude oil samples and two bitumen samples. The experimental viscosity data obtained at different temperatures and weight per cent of the bitumen samples were correlated with the viscosity equation of Singh et al. The viscosity of pure crude oils (for instance, Forcados crude oil) containing asphalted and deasphalted bitumen (Rush Lake and Plover Lake bitumen) increased by as much as $160 \%$ and $60 \%$ respectively.

However, the results obtained from correlating the viscosity data with the equation indicated that the discrepancies in measured data could be mainly attributed to the presence of asphaltenes, but the percent errors between measured and predicted viscosity were consistent for the entire samples. The results were identified the light crude oils as better alternative diluents for the production and transportation of heavy crude petroleum.

Keywords: Nigerian crude oil, asphaltenes, bitumen, hydrocarbon condensates, solvents, asphaltenes solubility, light crude oil, viscosity modeling.
\end{abstract}

\section{Introduction}

Pipeline transportation of heavy oil has been among the major challenges faced by the upstream petroleum industry. The high viscous nature of heavy oil, 
viscosity in the range of $1 \times 10^{4} \mathrm{cP}$, requires that the viscosity be reduced to approximately $400 \mathrm{cP}$ for its effective and efficient production and transportation. Researchers in this field have reported several techniques employed by industry to achieve reduction in heavy oil/bitumen viscosity such as the use of heating system in the formation and/or pipeline [1,2], addition of liquid diluents and injection of liquids or gaseous diluents into the formation, and the use of water and emulsion [3-5]. Although these methods, to an extent have been effective in reducing the oil viscosity the high costs of energy and diluents restrict their frequent applications. The diluents used by producers with greater success in large quantities are aromatic solvents, as in the Vapex process to reduce viscosity of heavy oil under reservoir conditions. Other classical diluents which have been used are naphthas, condensates, kerosene and light paraffins. These diluents, although environmentally friendlier and more cost effective than the aromatic solvents, have been identified with the problem of precipitation of asphaltenes from the heavy oils/bitumen which can cause severe clogging of wells and pipelines and totally halt production leading to loss in revenue [4].

Viscosity is an important physical parameter for crude oil that characterizes not only one of the rheological property, but also the quality of most crude oil products such as lubricating oils and lubricants [6]. Asphaltenes impact high viscosity to crude oils, negatively impacting production. Their precipitation and deposition are undesirable situation that can create a myriad of production problems. The choice of appropriate diluent is essential in maintaining the asphaltenes and other solids in solution during production operations. This study aims at the influence of light crude from different Nigerian oilfields in reducing the viscosity of pure bitumen and deasphalted bitumen. The effects of weight percent of asphaltenes on the viscosity of the bitumen-light crude oil mixtures are examined. The influence of composition and temperatures on the viscosities of the mixtures is correlated with independent and generalized viscosity model of Singh et al [7].

\section{Experimental methods}

The light crude oil samples used as diluents were obtained from oil wells in the following locations in the Niger Delta region of Nigeria; Umutu Flow station, Beryboye Flow station, Beniboye Flow station, Forcados field, Warri Terminal and Kaduna Refinery. Two bitumen samples, Rush Lake and Plover Lake, (from Alberta, Canada) were supplied by Alberta Research Council. The solvent npentane is analytical grade chemical (Sigma-Aldrich, HPLC grade, 99.9\%) commercially available and was used as received.

Asphaltene precipitation was carried out using 1:40 ml bitumen : n-pentane ratio. The mixture was agitated using a G10 gyrotary shaker for 24 hours, left to stand for two hours and filtered using a $7.0 \mathrm{~cm}$ whatman filter paper as described in ASTM 863-63. The procedure used to recover the deasphalted bitumen has been documented in our previous publication [8]. To prepare the mixtures of light crude oil containing $5 \mathrm{wt} \%$ to $40 \mathrm{wt} \%$ bitumen, a known amount of the bitumen was added quantitatively to the light crude oil in increment of $5 \mathrm{wt} \%$. 
The mixtures, contained in tightly closed $200 \mathrm{ml}$ sample bottles, were then placed in the shaker for 7 days. This was to ensure for complete dispersion of the bitumen and the homogeneity of the mixtures. The kinematic viscosity of the samples was determined with Canon-Finske opaque reversible capillary viscometer in accordance with the procedure in ASTM D-445-83-1986.

\section{Discussions of results}

Figures 1 and 2 illustrate the viscosity-temperature relationship for the pure light crude oils, and the mixtures that contained different $\mathrm{wt} \%$ of pure and deasphalted Rush Lake and Plover Lake bitumen. As expected, the results clearly show that the presence of asphaltenes, even in a small amount, in crude oil has a significant impact on the viscosity of the oil. The results are consistent with those obtained in our previous work with calorimetric method [8]. Figures 1 and 2 gave a true

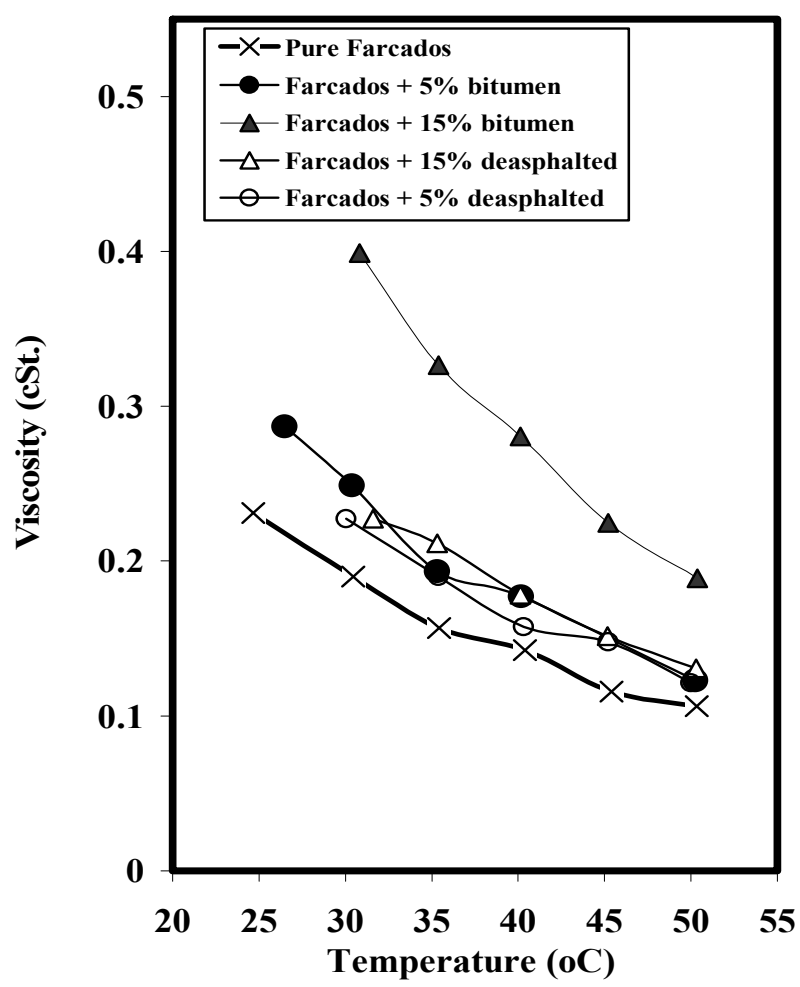

Figure 1: Viscosity-temperature relationship for Farcados crude oil with different $w t \%$ Rush Lake bitumen. 


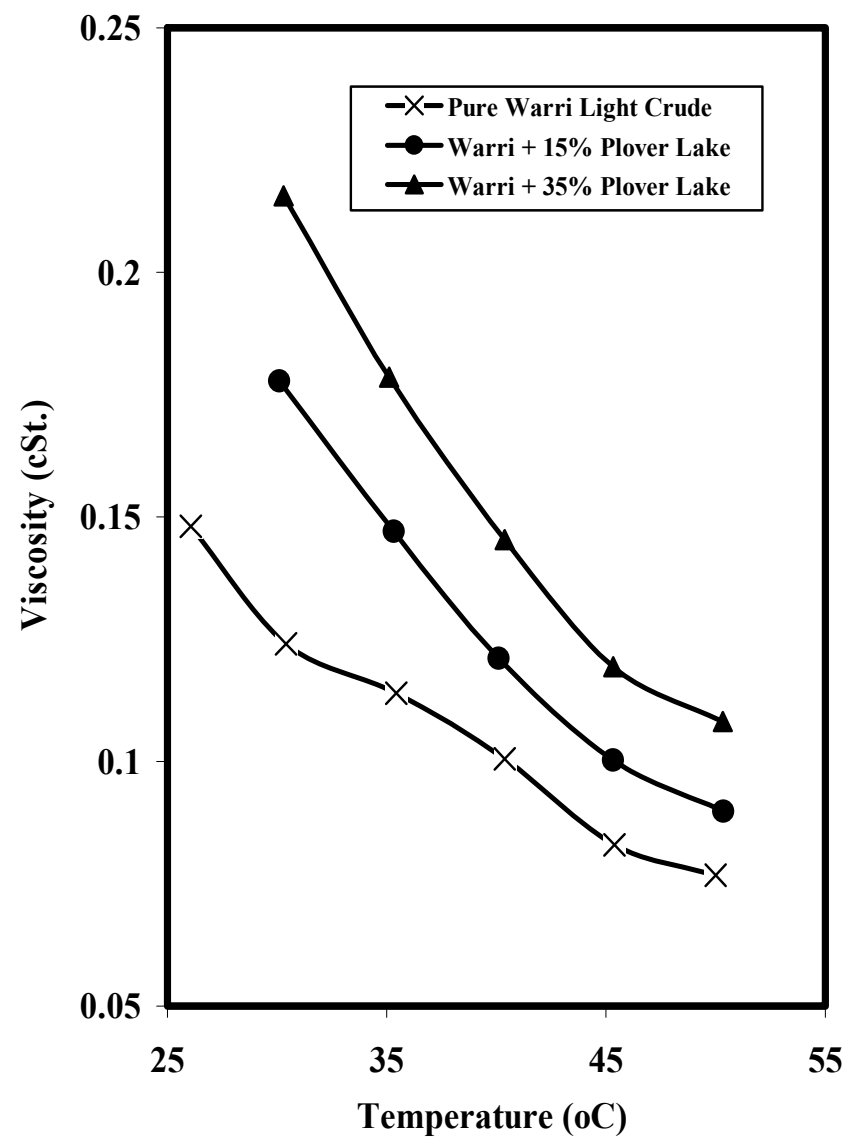

Figure 2: Viscosity-temperature relationship for Warri light crude oil with different $w t \%$ Plover Lake bitumen.

representation of the results observed with all the crude oil samples examined in this study. The light crude oils used contained no asphaltenes, and after blending with asphalted bitumen the mixtures remained homogeneous throughout the experiment. Mixtures examined contained as much as $40 \mathrm{wt} \%$ asphalted bitumen and $25 \mathrm{wt} \%$ deasphalted bitumen. For the light crude oil samples used in this study, the viscosity increases exponentially with higher weight percent of asphalted bitumen. Similar upward trend was observed with deasphalted bitumen, but with significant reduction in the percent increment as shown in Figures 3 and 4. The impact of asphaltenes on viscosity is clearly evident in Figure 3. With $20 \mathrm{wt} \%$ addition of asphalted bitumen the oil viscosity at $30^{\circ} \mathrm{C}$ increased by approximately $160 \%$ and by only $60 \%$ for the same amount of deasphalted bitumen. This trend was observed over the studied temperature range for the entire mixtures, as shown in Figure 4. 


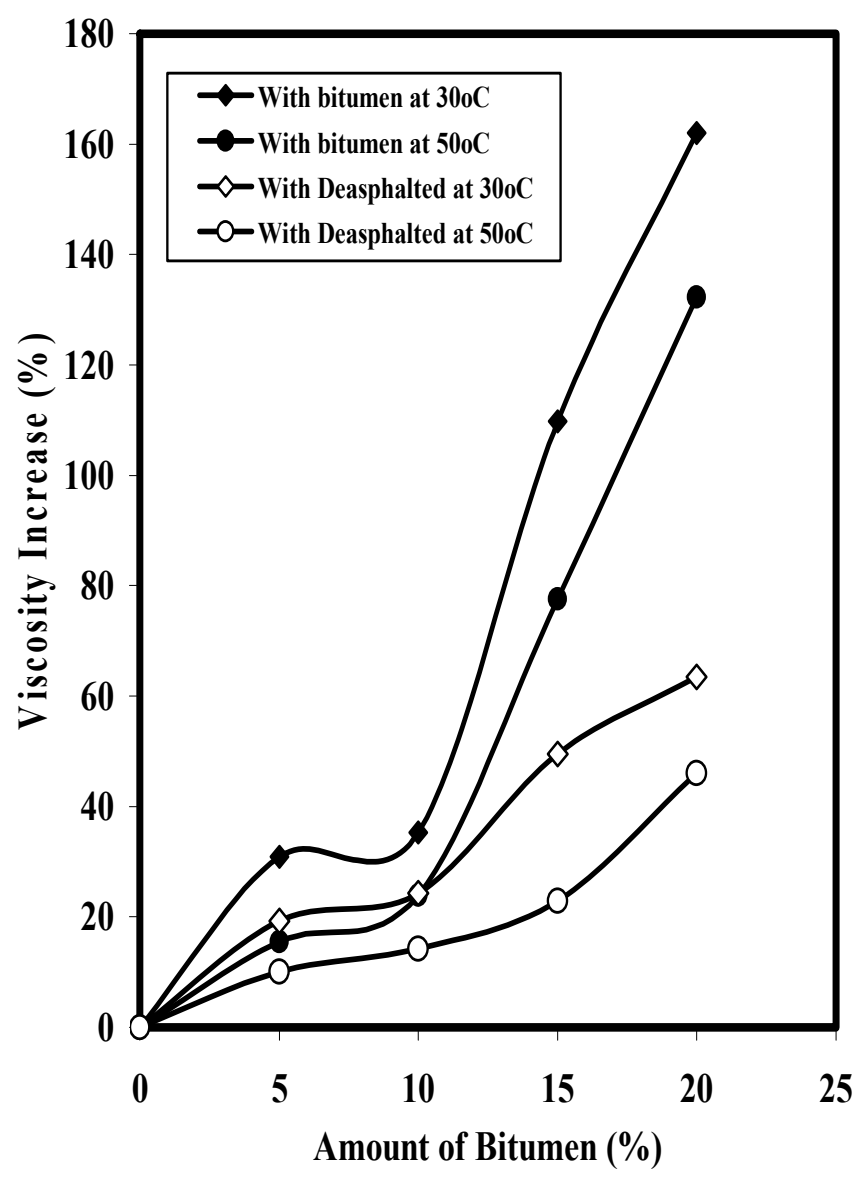

Figure 3: Percent increase in viscosity of Farcados light crude with different $\mathrm{wt} \%$ of asphalted and deasphalted bitumen.

It is evident from the results that the presence of asphaltenes is mainly responsible for high viscosity characteristics of crude petroleum. The results show also that at higher temperature there is no significant difference in the percent reductions in viscosity between the samples (light crude oils, asphalted mixtures and deasphalted mixtures). These observations can be attributed to the fact that asphaltenes structures are hardly affected at these temperatures to have significant impact on viscosity, as a result of heat transfer to diluents. It is well known that temperature has a strong effect on viscosity of heavy petroleum. At high temperatures the high molecular weight hydrocarbon components of the heavy petroleum disentangles, breaking the physical bonds and in most cases the chemical structures of the asphaltenenes and other solids, and by so doing the oil viscosity is reduced [9]. However, our results illustrate that at the temperature range studied, viscosity reduction of heavy petroleum with diluents is mostly 


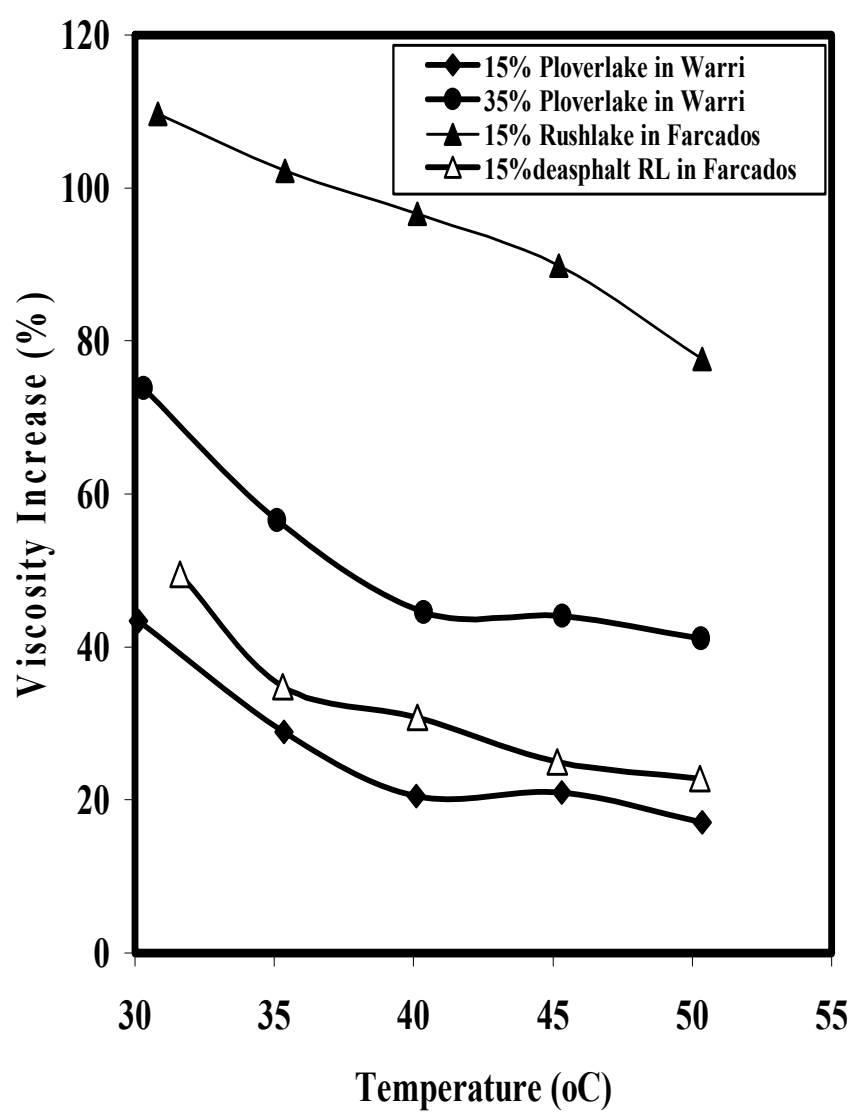

Figure 4: Effect of temperature on percent increase in Viscosity of light crude oils with asphalted and deasphalted bitumen.

governed by molecular disentanglement through diffusion phenomenon rather than temperature effects on the chemical structures of asphaltenes and other heavy components in the mixtures.

The viscosity-temperature relationship for different Nigerian light crude oil samples are shown in Figure 5, and in Figures 1 and 2 for those containing different weight percent of asphalted and deasphalted Rush Lake and Plover Lake bitumen. Singh et al [7] proposed a modified version of the Roelands Equation to correlate the viscosity of light oils as follows:

$$
\log \eta=\frac{b}{1+\left(\frac{T-37.78}{310.93}\right)^{S}}+C
$$

$\eta$ is kinematic viscosity (cSt), $T$ is temperature $\left({ }^{\circ} \mathrm{C}\right), C$ is given as $-0.8690, b$ is the characterization parameter defined as: $b=\log _{10} \eta_{37.78^{\circ} \mathrm{C}}-C$, and $S$ is the shape 


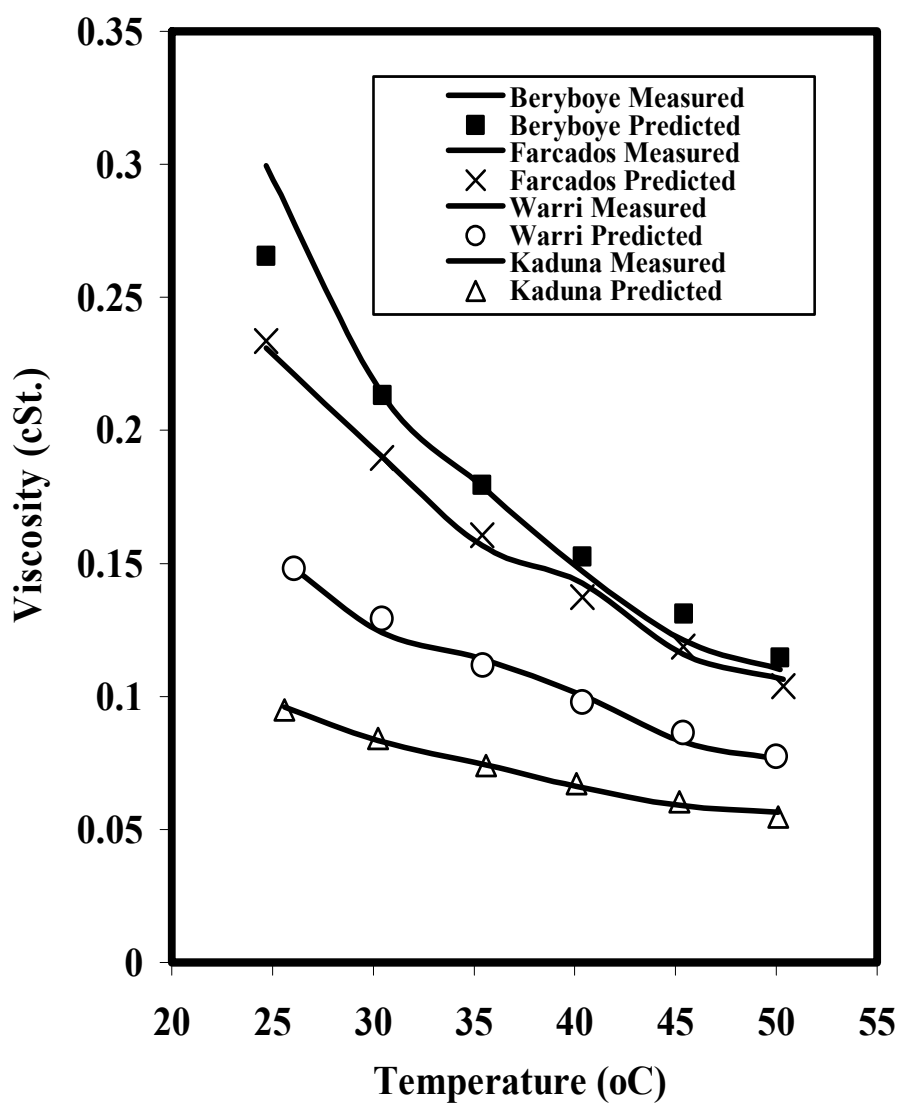

Figure 5: Comparison of measured and predicted viscosity for different Nigerian Light crude oils.

factor which relates to the characterization parameter as follows: $S=0.28008^{*} b-$ 1.6180. The viscosity data were fitted with Eq.(1) to obtain new parameters, for $C=-2.1042$ and $S=.2800 * 3.0166$, with regression coefficient, $R^{2}$, of 0.998 . With the optimized characterization parameters, the equation was able to better estimate the viscosities of the light crude oil-bitumen mixtures. Figure 5 shows the comparison between measured and predicted viscosities at different temperatures for different samples. Except for Beryboye light crude at $25^{\circ} \mathrm{C}$ there is a good match between measured and predicted viscosities for all the examined light crude oil samples. The correlation percent errors at different temperatures for the light crude samples, and mixtures containing different weight percent of either asphalted or deasphalted bitumen are compared in Figures 6-8. The percent errors were within $4 \%$ for pure Farcados light oil (Figure 6) and Warri 


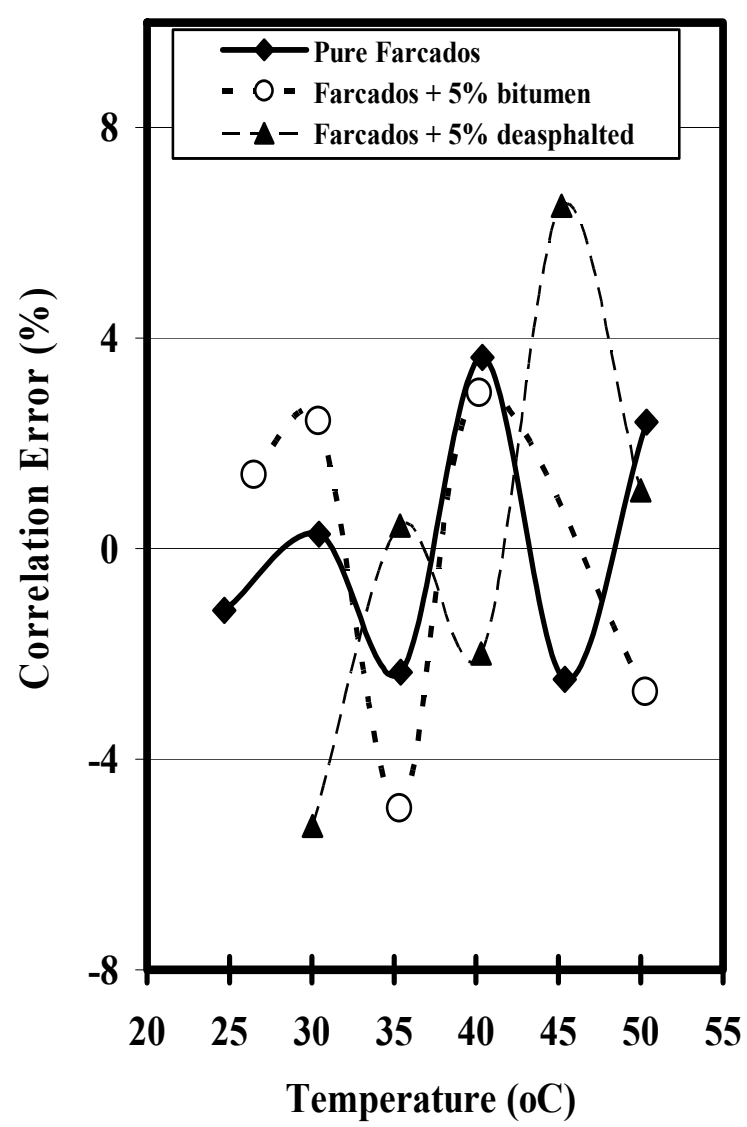

Figure 6: Deviations between measured and predicted viscosity at different temperatures for $5 \mathrm{wt} \%$ Rush Lake in Farcados crude.

light oil (Figure 8). Similar results were obtained for the entire pure light oil sample used in this study. The percent average deviations for the samples are given in Table 1. The results show that the light oil viscosity characteristics were not affected by the addition of asphalted and deasphalted bitumen up to $40 \mathrm{wt} \%$. As mentioned earlier, the addition of bitumen increased the viscosity of the light oils (Figures 1 and 2), with asphalted bitumen nearly tripled the increase in viscosity obtained with deasphalted bitumen.

Besides this phenomenon, the overall viscosity behavior of the mixtures remained similar to that of the pure light crude oils even at high temperatures. The percent errors obtained with the viscosity equation (Eq.(1)) for the mixtures illustrate that the mixtures examined were homogeneous, as the predicted viscosity closely matched the measured viscosity. In many cases, better match between measured and predicted viscosities were obtained for the mixtures than for pure light crude oil samples. The percent average deviations for these 


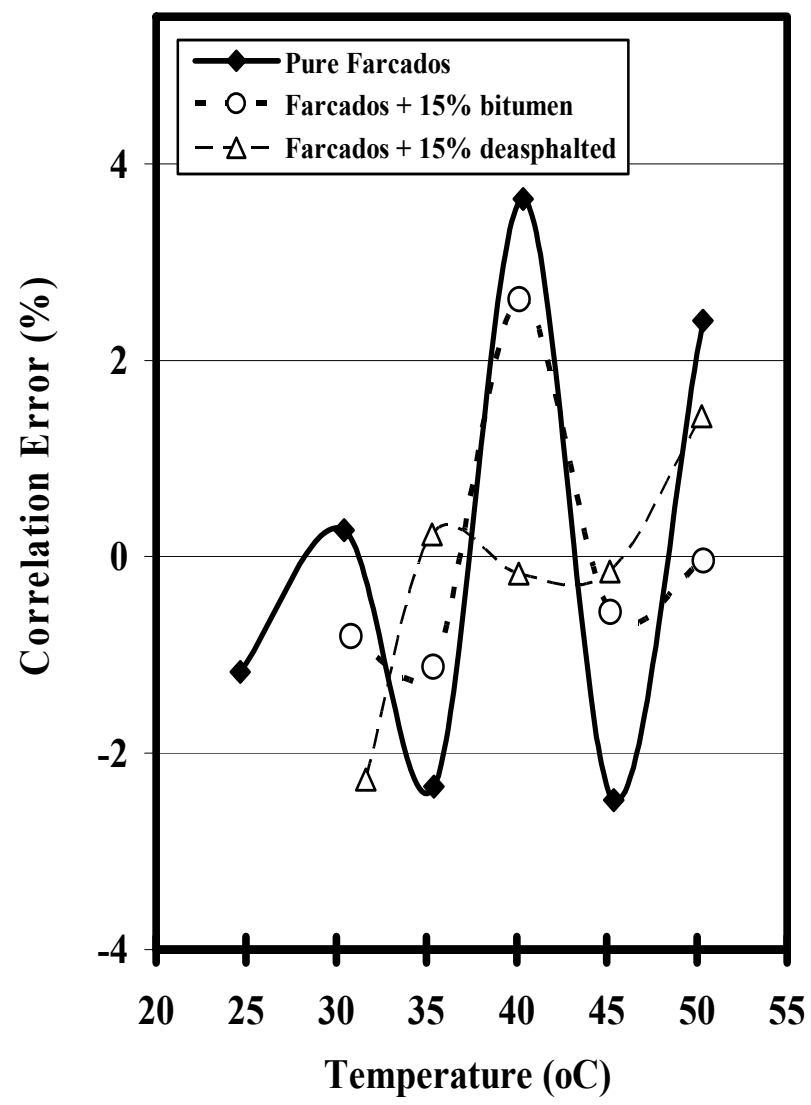

Figure 7: Deviations between measured and predicted Viscosity at different temperature for $15 \mathrm{wt} \%$ Rush Lake in Farcados Crude.

samples are compared in Table 1. The results illustrate that light oil is arguably a good solvent for bitumen, as the asphaltenes and other solids (resins, maltenes, heavy saturates) appeared to be soluble in the oils. It is worthy to note that the light crude oils used in this study contain no asphaltenes, and the compositions are mainly low molecular weight paraffins. Aromatic solvents, such as toluene and xylene, have been long identified as the best solvent for reducing viscosity of heavy oil/bitumen due to their ability to maintain asphaltene molecules in solution. For the light crude oils used here, molecular diffusivity, intermolecular attraction and low hydrogen bonding rather than molecular polarity might be the crucial factors that characterize the oil as good solvent to reduce the viscosity of bitumen. 


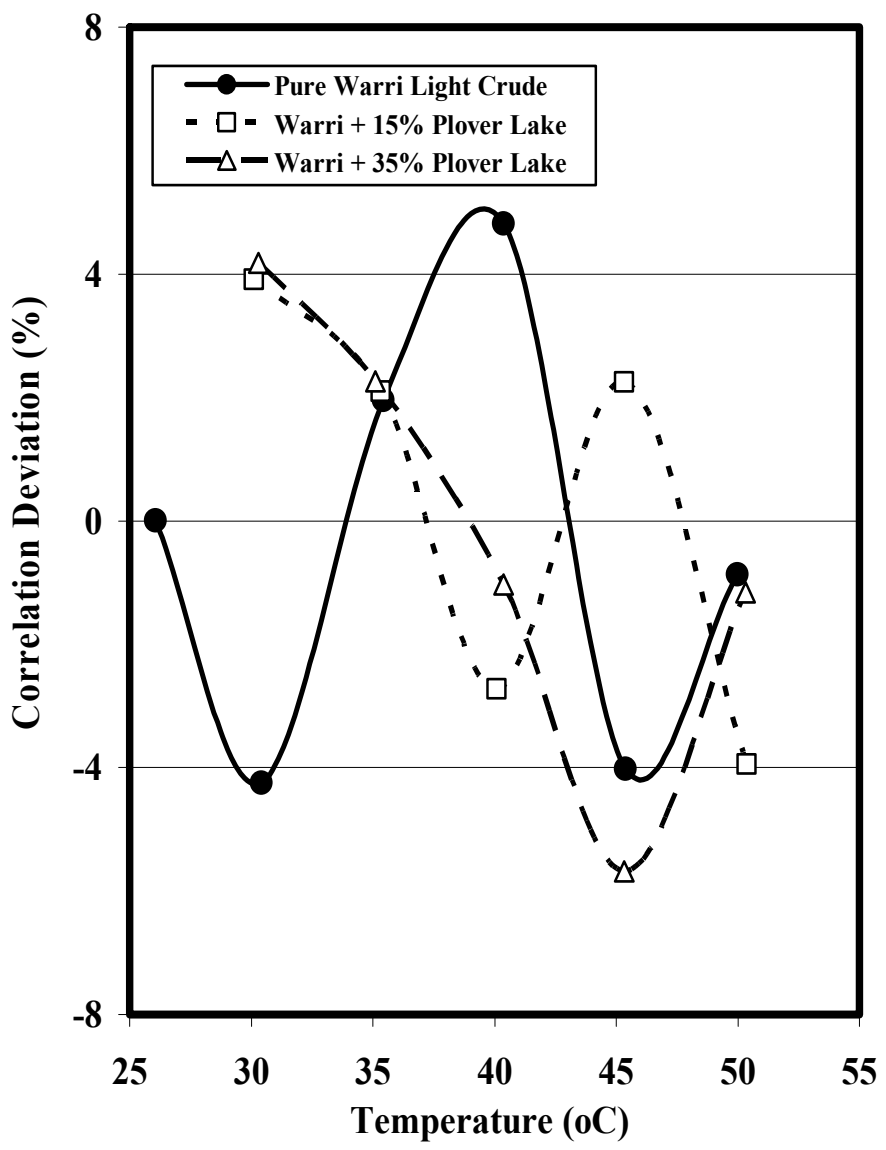

Figure 8: Deviations between measured and predicted viscosity at different temperatures for Plover Lake in Warri crude oil

\section{Conclusions}

The most important benefit of this study is that knowing the relatively huge reserve of non-asphaltic light crude oils and the untapped bitumen and heavy oil resources in Nigeria, we have shown that non-asphaltic light crude oils can be successfully used in production and pipeline transportation of bitumen. The results show that for up to $40 \mathrm{wt} \%$ bitumen the viscosity characteristics of the mixtures remain identical to that of the light crude oil, an indication that the asphaltenes and other resinous solids remain soluble in the mixtures. The viscosity correlations for both pure light oil samples and the mixtures gave similar percent deviations with an overall absolute deviation of $2.6 \%$; making light crude oils a good diluent for bitumen. 
Table 1: Percent average deviations between measured and predicted viscosity values for pure and mixed samples.

\begin{tabular}{|c|c|c|}
\hline Oil Sample & $\begin{array}{c}\text { Data } \\
\text { Points }\end{array}$ & Mean \\
\hline Beryboye light crude & 5 & 4.28 \\
Farcados light crude & 5 & 2.25 \\
Beniboye light crude & 5 & 2.93 \\
Wari light crude & 5 & 2.98 \\
Kaduna light crude & 5 & 1.35 \\
Farcados-5\%-Rushlake bitumen & 5 & 2.60 \\
Farcados-10\%-Rushlake bitumen & 5 & 1.74 \\
Farcados-15\%-Rushlake bitumen & 5 & 1.20 \\
Farcados-20\%-Rushlake bitumen & 5 & 2.17 \\
Farcados-5\%-Deasphalted bitumen & 5 & 3.31 \\
Farcados-10\%-Deasphalted bitumen & 5 & 1.95 \\
Farcados-15\%-Deasphalted bitumen & 5 & 2.85 \\
Farcados-20\%-Deasphalted bitumen & 5 & 1.82 \\
Farcados-25\%-Deasphalted bitumen & 5 & 3.13 \\
Warri-15\%-Plover Lake Bitumen & 5 & 3.90 \\
Warri-35\%-Plover Lake Bitumen & 5 & 2.86 \\
Average Absolute Deviation (\%) & $\mathbf{8 5}$ & $\mathbf{2 . 6 0}$ \\
\hline
\end{tabular}

\section{Acknowledgements}

This work was funded in part by NSERC, Canada, and PTF, Nigeria. The supports of American University of Nigeria (AUN), and NNPC Research Lab (Port Harcourt), are highly appreciated. Ours thanks to Harrigan A. Pepple (NNPC, Warri), MacDonald I. Bara-Hart (NNPC, Benin), and Samuel O. Robinson (AGIP Oil, Umoku) for their various contributions in the acquisition of field samples and related data.

\section{References}

[1] Urquhart, R.D. Heavy Oil Transportation: Present and Future. J. Can. Petrol. Technol., 25 (2), pp.68-71, 1986.

[2] Chang, C., Nguyen, Q.D., \& Ronningsen, H.P. Isothermal start-up of pipeline transporting waxy crude oils. J. Non-Newt. Fluid Mech., 87, pp.127-54, 1999. 
[3] Mokrys, I.J., \& Butler, K.M. In-Situ Upgrading of Heavy Oils and Bitumen by Propane De-Asphalting:The VAPEX Process. Paper SPE 25452 presented at SPE Symposium, Oklahoma City, Oklahoma, March 21-23, 1993.

[4] Das, S.K., \& Bulter, R.M., Mechanism of the Vapour Extraction Pocess for Havy Oil and Bitumen. J. Petrol. Sci., 12, pp. 219-231, 1995.

[5] Byran, J.,\& Kantzas, A. Enhanced Heavy-Oil Recovery by AlkalineSurfactant Flooding, Paper SPE 110738 presented at SPE Tech. Conf. \& Exhibition, Anhein, California, Nov. 11-14, 2007.

[6] Sanchez, J.H. \& Mansoori, G.A. Prediction of the Phase Behavior of Asphaltne Micelle/Aromatic Hydrocarbon Systems. Petrol. Sci. \& Technol,16 (3\&4), pp.377-394, 1998.

[7] Singh, B., Miadonye, A. \& Puttagunta, V.R. Modelling the Viscosity of Middle-East Crude Oil Mixtures. Ind. \& Engr. Chem. Res.,32 (9), pp.21832186, 1993.

[8] Miadonye, A., Secka, K.A., Cyr, J. \& Britten, A. Study of thermo-physical properties of bitumen in hydrocarbon condensates. WIT Transact. on Modelling and Simulation, Numerical Methods, 48, pp.125-134, 2009.

[9] Khan, M.R. Rheological properties of heavy oil emulsions. Energy Source, 18, pp.385-391, 1996. 